UDC: $330.101: 316.42 / 43$

DOI: 10.26697/ijes.2019.4.37

\section{Team Social Development Indicators}

Associate Professor Litvinenko A. V. ${ }^{\mathbf{1}}$

${ }^{1}$ Simon Kuznets Kharkiv National University of Economics, Ukraine

\section{Abstract \\ Background:}

The diagnosis of social development and the determination of its level should include constant monitoring of these characteristics. As in purely theoretical terms, and in the direct activities of enterprises, today there is no single approach to the generally accepted approach to determining the level of social development. This is due to the significant difficulties accompanying the diagnosis process.

Certain difficulties in the calculation are some indicators that have qualitative characteristics, and therefore are not devoid of some subjectivity, that is, the comparison should be carried out not on the absolute values of the indicators, but on the basis of their relative variation.

The definition of the level (indicator reflecting this level) of social development (individual team, enterprise, region, etc.) should, of course, be supplemented by some other calculations, in other words, there is a need for a comparative comprehensive assessment of the level of social development of the object for a certain period of time (in dynamics), and comparison with similar indicators of other objects.

The assessment of social development should be based on one indicator, which is accepted as a determinant. However, the multidimensional nature of social development makes it necessary to describe it from different sides, that is, in a multidimensional space, the dimension of which is determined by the number of output characteristics.

One of the possible options for the development of a single generalizing indicator of social development is the construction of a generalizing indicator of quality. Modern experience of constructing this indicator and conducting a significant number of studies have proved the possibility of its using in various spheres of public life.

The purpose of research is to develop a methodology for determining the generalized indicator of social development of the collective.

\section{Methods:}

The theoretical and methodological foundations of the study are expert and statistical methods, the method of analysis of hierarchies and the method of decomposition - in the development of a methodological approach to assessing the level of social development of the collective.

\section{Results:}

The content of the element-by-element system of social development of the collective is specified.
A methodological approach to assessing the level of social development of the collective on the basis of desirability functions is developed.

\section{Conclusions:}

The definition of a generalizing indicator of the quality of social development is advisable to carry out in several stages from the descriptive statistics of changes in the values of indicators of signs of the object to the definition of a generalizing function of the desirability of signs of the object. With their help, individual indicators of social development are transformed into an immeasurable scale. This stage of formalization is necessarily preceded by parametric analysis of object parameters.

Appropriate desirability function of certain characteristics of an object form a summary measure of the quality of the relevant characteristic and, therefore, separate functions allow to construct the generalized function of desirability of the object attributes, which, in turn, is the final evaluation of the characteristics of an object. This generalizing indicator is a synthetic assessment of the level of social development of a certain object (collective, enterprise, region, etc.).

Thus, the desirability functions obtained in this way demonstrate the regularities of development of both elementary and complex features during the considered period. The resulting system of values forms a system of indicators that objectively describe the state and dynamics of social development of a particular object.

\section{Information about the author:}

Litvinenko Andrey Volodymyrovych - candidate of economic Sciences, Associate Professor, Associate Professor of the Department of Economic Theory and Economic Policy, Simon Kuznets Kharkiv National University of Economics, Kharkiv, Ukraine.

Research interests: the development of the social state, social partnership; https://orcid.org/0000-0001-59735173.

Corresponding Author:

Litvinenko Andrey Volodymyrovych

Corresponding Author's Email:

in4.andrey@gmail.com 